\title{
The role of platform quality and publicly owned platforms in the free-to-air broadcasting industry
}

\author{
Miguel González-Maestre • Francisco Martínez-Sánchez
}

Received: 8 March 2012 / Accepted: 16 August 2013 / Published online: 1 September 2013

(C) The Author(s) 2013. This article is published with open access at SpringerLink.com

\begin{abstract}
In this study, we consider the role of a publicly owned platform and programme quality in the free-to-air broadcasting industry. We compare the equilibrium levels of advertising under private and mixed duopoly competition, and show that the connection between programme quality and advertising incentives is drastically different in each scenario. We also consider the welfare implications of our analysis and generate policy implications regarding the optimal level of government intervention in the broadcasting industry.
\end{abstract}

Keywords Quality · Mixed duopoly · Advertising · Media

JEL Classification $\mathrm{L} 11 \cdot \mathrm{L} 33 \cdot \mathrm{L} 82 \cdot \mathrm{M} 37$

We thank the Co-editor Guillermo Caruana, and two anonymous referees for very helpful comments, and participants at the Jornadas de Economía Industrial (Madrid), EARIE Conference (Stockholm), ASSET Meeting (Alicante), and Encuentro de Economía Aplicada (Sevilla). We acknowledge financial support from Fundación Séneca, Agency of Science and Technology of the Region of Murcia, under project 11885/PHCS/09, and the Spanish Ministerio de Economía y Competitividad, under projects ECO2012-31962, ECO2011-28501, and ECO2010-19830.

M. González-Maestre $(\bowtie)$

Departamento de Fundamentos del Análisis Económico,

Universidad de Murcia, 30100 Murcia, Spain

e-mail: mmaestre@um.es

F. Martínez-Sánchez

Departamento de Métodos Cuantitativos para la Economía y la Empresa,

Universidad de Murcia, 30100 Murcia, Spain

e-mail: fms@um.es 


\section{Introduction}

This study addresses the role of public intervention in the free-to-air broadcasting industry. In fact, public intervention in broadcasting markets has been particularly justified when advertising is the only method of commercial provision. As suggested by Coase (1966), in the absence of subscription television, public policy can increase social welfare by improving the quality and diversity of the available programming. A basic ingredient of the justification of this public regulation is usually associated with the need of diminishing the nuisance of excessive advertising. The rapid technological advances in the broadcasting and communication industries have enhanced the debate on the role of public intervention in broadcasting industries (see, among others, Armstrong 2005). Moreover, this debate has become particularly relevant as a result of recent controversial policy decisions within the EU. Particularly remarkable is the decision by the public TV platform in France (followed more recently by its counterpart in Spain) to eliminate advertising as a method of financing. ${ }^{1}$

In this study, we consider the role of programme quality and a publicly owned platform in the context of the free-to-air broadcasting industry. Publicly owned platforms are prominent in the broadcasting media industry in many Western countries. The empirical relevance of this presence is observed in Bel and Domènech (2009) (table 1 p. 167), and more recently, in Sanz (2012). In particular, we note the existence of one or more national publicly owned TV platforms in Italy, Germany, France, UK, Switzerland and Spain.

Despite the above-mentioned evidence, there is a surprising lack of research into the role of publicly owned platforms in the media industry and its connection to the use of advertising. A remarkable exception is the work by Kind et al. (2007). As noted by those authors, consideration of the role of publicly owned TV as a method of broadcasting market regulation is natural, in view of the problems associated with alternative regulation policies. In particular, lobbying pressures, technological progress and increased globalisation appear to have increased the difficulty of the optimal implementation of the direct regulation of advertising time in private platforms. In a model including horizontal product differentiation, these authors show that a welfaremaximising publicly owned TV channel generates less advertising than private ones if and only if the degree of the TV platforms' horizontal differentiation is sufficiently large. The intuition of their results is that if the broadcasting products are very close substitutes, then audiences will be very sensitive to advertising, and as a consequence, private advertising incentives will be too small from the social welfare perspective.

A mixed duopoly incorporating advertising regulation in the broadcasting industry is considered by Stühmeier and Wenzel (2012) in the context of a Hotelling model including horizontal differentiation. They evaluate the effects of a binding advertising cap on competition for viewers and advertisers in a duopoly framework. They find that the regulation of advertising can increase profits. This result is explained by competing

\footnotetext{
1 In substitution for this source of financing, the French government has established a tax on the revenues earned by private TV and telecom platforms, a decision that is currently under investigation by the European Commission.
} 
channels' failure to completely account for the effect that their choice has on rivals' advertising prices, which is resolved through exogenous regulation.

With their empirical approach, Alcock and Docwra (2005) develop a stochastic oligopoly model calibrated for the Australian broadcast TV market. They find that the presence of a public platform can generate positive outcomes for viewers and other market suppliers simultaneously because it increases viewers' choice and total market size. More recently, Bel and Domènech (2009) have undertaken an empirical analysis in the Spanish broadcasting industry and found that advertisers create a negative externality to viewers that tends to be mitigated by the presence of publicly owned platforms.

The analysis of advertising in broadcasting media industries with private platforms has been considered extensively in the recent literature. ${ }^{2}$ In particular, Gabszewicz et al. (2004) consider two private TV-platforms that derive their profits from advertising and show that the platforms' profiles become closer as advertising aversion becomes stronger. Anderson and Coate (2005) show that advertising levels may be too low or too high with respect to the socially optimal level, depending on the nuisance cost to viewers, the substitutability of programmes and the expected benefits enjoyed by advertisers as a result of contacting viewers.

The role of advertising quality is considered by Gantman and Shy (2007). Those authors assume two types of viewers: those whose utility increases in the number of broadcasted advertisements and, those whose utility is unaffected by the number of advertisements they are exposed to. They show that if the improvement of advertising quality is profitable for the advertising firms, it is unprofitable for TV platforms. Peitz and Valletti (2008) analyse the comparisons between the pay-TV setting, in which platforms obtain revenue from advertising and from viewers, and the free-toair setting, in which platforms obtain all revenues from advertising. They show that if viewers strongly dislike advertising, advertising intensity is greater in a free-to-air setting and that free-to-air platforms tend to provide less differentiated content. In contrast, pay-TV platforms always maximally differentiate their content.

Crampes et al. (2009) consider the effects of advertising on entry into the media industry. They show that under constant or increasing returns to scale in the audience, the entry level is excessive and the advertising level is insufficient.

Most of these previous contributions focus on the combination of advertising and horizontal product differentiation among private platforms in two-sided markets. In contrast to these previous contributions, our model considers two relevant aspects of the broadcasting industry simultaneously:

First, in addition to horizontal differentiation, we also assume the presence of differences in programme quality, measured in terms of viewers' utility. In the previous literature, only Armstrong (2005), Crampes et al. (2009), and Lin (2011) analyse the role of program quality in the broadcasting industry. In particular, Armstrong (2005) and Lin (2011) compare the equilibrium quality levels associated with the free-to-air duopoly regime and subscription, whereas Crampes et al. (2009) analyse the effects of endogenous quality improvements on entry. However, these previous contributions assume

\footnotetext{
${ }^{2}$ See the interesting surveys by Anderson (2007) and Anderson and Gabszewicz (2006) on advertising in the media.
} 
the existence of competition among symmetric private platforms, whereas we consider the role of a publicly owned platform in the presence of asymmetric quality levels. ${ }^{3}$

Second, our model analyses the combined role of publicly owned television and advertising in the broadcasting markets. As explained above, only Kind et al. (2007) have analysed this issue from a theoretical perspective. However, in contrast to this previous contribution, which is focused on a model of a representative consumer and horizontal differentiation, our approach combines both horizontal and vertical differentiation among platforms in the context of a linear Hotelling model. Specifically, the aim of our paper is twofold:

1) We first analyse the optimal advertising decision of the public platform, considering two welfare effects: (i) a direct effect, measured in terms of advertising revenues and nuisance costs, and (ii) an indirect effect, which works through the distribution of the audience among the broadcasting platforms. As we will show, this indirect effect depends on both the degree of product differentiation and the quality differential between platforms. Interestingly, as in the model created by Kind et al. (2007), in our model, the equilibrium level of advertising by the publicly owned platform can be positive even if advertising has a direct socially harmful effect. However, whereas these authors focus on the effects exerted by the degree of horizontal product differentiation on the advertising comparisons between the private platform and publicly owned platform, our model considers the role of both horizontal and vertical (quality) differentiation explicitly. We show that the quality differential between the platforms is crucial in optimal advertising choice on the part of the public platform. In particular, we find that the greater the public platforms' quality differential and the higher the relative harmful effect of advertising, the more likely it is that an "advertising-free" public platform is optimal. Intuitively, by decreasing its advertising, the publicly owned platform increases its audience, which is socially beneficial if its quality differential is large. These results show that the explicit consideration of the quality differential in our model provides new insights with respect to the previous models, such as Kind et al. (2007), that have focused on only the role of horizontal differentiation. ${ }^{4}$

2) Second, we compare the equilibrium levels of advertising in two settings: a private duopoly, which includes two private profit-maximising platforms, and a mixed duopoly, in which a welfare-maximising publicly owned platform competes with a private platform. ${ }^{5}$ We identify the conditions under which privatisation is socially desirable and show that the connection between programme quality and advertising

\footnotetext{
${ }^{3}$ Lin (2011) also considers a third regime in which a pay-TV broadcaster competes with one free-TV broadcaster.

4 Therefore, whereas Kind et al. (2007) focus on the interplay between the degree of horizontal differentiation and the number of competitors, to explain the advertising policy of the publicly owned platform, our model focuses on the combined role of horizontal differentiation and quality differentials.

5 Few papers consider the existence of a public-owned firm in a model of horizontal product differentiation. Kumar and Saha (2008) show that unless public ownership exceeds a critical level, maximal differentiation continues to hold and social welfare does not improve with public ownership. Moreover, Sanjo (2009) analyses price choice and sequential price choice simultaneously and shows how the degree of a publicly owned firm's privatization influences social welfare in a mixed duopoly market. Finally, Martínez-Sánchez (2011) uses the model developed by Sanjo and shows that in the location game, in which firms set prices simultaneously, social welfare depends on the degree of privatisation and is only maximised if the partially privatised firm is a fully publicly owned firm.
} 
incentives differ drastically between the two scenarios. In particular, we show that the presence of a public platform is socially desirable if its quality differential is positive and advertising is harmful or if its quality differential is negative and advertising is beneficial. However, it is also shown that there are conditions under which privatisation is socially better than a mixed duopoly. Intuitively, privatisation might act as a commitment device that allows the government to improve the welfare level through its effect on the response of the rival platform.

The main insight provided by our analysis is that the interplay between the social cost of advertising and the quality differential between platforms is crucial in the assessment of both the equilibrium level of advertising and the social desirability of a publicly owned platform.

The remainder of the paper is organised as follows: Sect. 2 presents a spatial duopoly market with private platforms, Sect. 3 analyses the model with a mixed duopoly in which one of the competitors is a publicly owned firm that maximises welfare, Sect. 4 considers advertising and welfare comparisons of the two models, and Sect. 5 concludes.

\section{The private duopoly model}

We will assume two private platforms, each located at one extreme of a linear market of length 1 . There is a mass of consumers of measure 1, distributed uniformly along this linear market. Each consumer, indexed by $x \in[0,1]$, chooses either one unit of good or zero. The utility of consumer $x$ if she/he watches platform $i=1,2$ is provided by the function

$$
u\left(v_{i}, a_{i}, x\right)= \begin{cases}v_{1}-\delta a_{1}-t x & \text { if } i=1 \\ v_{2}-\delta a_{2}-t(1-x) & \text { if } i=2\end{cases}
$$

where $v_{i}$ is the gross utility from the chosen platform, $\delta$ is the parameter representing the disutility or nuisance cost per unit of advertising (denoted by $\left.a_{i}\right),{ }^{6}$ and $t$ is the transport cost per unit of the distance of departure from his/her favourite TV program. Moreover, $t$ can be interpreted as the degree of substitutability, so a higher $t$ indicates that platforms are less substitutable.

Let us define $x_{1}$ as the marginal consumer who is indifferent between watching/listening to platform 1 or platform 2 . Thus, $x_{1}$ is provided by the following condition:

$$
v_{1}-\delta a_{1}-t x_{1}=v_{2}-\delta a_{2}-t\left(1-x_{1}\right)
$$

In addition, we define $x_{2}=1-x_{1}$. Thus, we can obtain the demand for firm $i$, which is as follows:

\footnotetext{
${ }^{6}$ Assuming $\delta>0$ is consistent with the empirical evidence provided by Wilbur (2008). This author finds that viewers dislike advertising in the TV industry.
} 


$$
x_{i}\left(a_{i}, a_{j}\right)=\frac{v_{i}-v_{j}+t-\delta\left(a_{i}-a_{j}\right)}{2 t}, i=1,2, j \neq i .
$$

As in Gabszewicz et al. (2004), we consider the advertising market to be perfectly competitive, so advertisers' profits are zero. However, we assume that the profit obtained by each platform consists of the advertising revenue, so this is provided by $\pi_{i}=\gamma a_{i} x_{i}$, where $\gamma$ can be interpreted as the revenue per ad per viewer, which in turn, is assumed to be proportional to advertising level. ${ }^{7}$ By substituting the demand function (1) in the definition of profits, we can obtain the following:

$$
\pi_{i}\left(a_{i}, a_{j}\right)=\gamma a_{i} \frac{v_{i}-v_{j}+t-\delta\left(a_{i}-a_{j}\right)}{2 t}, i=1,2, j \neq i .
$$

Let $z \equiv\left(v_{1}-v_{2}\right) / t$ be the (relative) quality differential between both platforms; thus, a higher $z$ could be the result of a higher quality differential or a higher degree of substitution between platforms. Let $k \equiv \gamma / \delta$ be the relative value between the revenue per ad per viewer and the nuisance cost. Note that $\gamma$ is the social value of advertising, whereas $\delta$ is its social cost. Therefore, from the social welfare perspective, the direct effect of advertising is neutral if $k=1$, beneficial if $k>1$, and harmful if $k<1$. Let us investigate the Nash equilibrium (NE) in advertising levels. To guarantee that NE levels of market shares are positive for both platforms, we assume that $z \in(-3,3)$ in the remainder of this section. Using the first order conditions of profit maximisation, we can obtain the reaction function of each firm:

$$
a_{i}^{B R}\left(a_{j}\right)=\frac{v_{i}-v_{j}+t}{2 \delta}+\frac{a_{j}}{2}, i=1,2, i \neq j,
$$

which yields the following NE levels of advertising, market shares and profits:

$$
\begin{array}{ll}
a_{i}^{*}=\frac{v_{i}-v_{j}+3 t}{3 \delta} ; \quad a^{*}=a_{1}^{*}+a_{2}^{*}=\frac{2 t}{\delta} ; \\
x_{i}^{*}=\frac{v_{i}-v_{j}+3 t}{6 t} ; \quad \pi_{i}^{*}=\frac{k\left(v_{i}-v_{j}+3 t\right)^{2}}{18 t} .
\end{array}
$$

Considering (4), it is clear that platforms implement more advertising and obtain a larger audience when their quality is higher. They thus increase their profits because higher quality allows for the softening of advertising competition because advertising level plays the same role as price in the well-known Hotelling model, as demonstrated by Gabszewicz et al. (2004). Proposition 1 summarises these results.

Proposition 1 In the case of competition among private platforms, the following properties hold at the NE of the game:

i) The advertising levels, market share and profit of platform i increase with its own quality and decrease with the quality of its rival.

ii) Total advertising level is independent of quality levels.

\footnotetext{
7 In particular, we assume that platforms do not compete for advertisers. This assumption is common in the literature on two-sided markets and is known as competitive bottleneck (Armstrong 2006).
} 
Proof See Appendix.

In addition, (4) indicates that the following result holds:

Proposition 2 In the case of competition among private platforms, each platform's profit decreases with the degree of substitutability among platforms, increases with the revenue per ad per viewer and decreases with the nuisance cost of ads.

Proof See Appendix.

According to Proposition 2, lower substitutability among platforms implies that these platforms earn a higher profit because competition in ads is softened when platforms are less substitutable and the market is fully covered. In contrast, we find that a higher nuisance cost implies lower profits as a result of viewers' incentives to switch being higher with a high nuisance cost because the utility that viewers obtain from watching a TV-platform decreases with the nuisance cost. ${ }^{8}$

Consumer surplus $(C S)$ is calculated as follows: ${ }^{9}$

$$
C S=v_{1} x_{1}-\delta a_{1} x_{1}-t \int_{0}^{x_{1}} x d x+v_{2}\left(1-x_{1}\right)-\delta a_{2}\left(1-x_{1}\right)-t \int_{x_{1}}^{1}(1-x) d x
$$

We now calculate social welfare $(W)$, which is defined as the sum of platforms' profits $\left(\pi=\pi_{1}+\pi_{2}=\gamma a_{1} x_{1}+\gamma a_{2}\left(1-x_{1}\right)\right)$ and consumer surplus

$$
W=\pi+C S=(\gamma-\delta) a_{2}+\left(v_{1}-v_{2}+t+(\gamma-\delta)\left(a_{1}-a_{2}\right)\right) x_{1}-t x_{1}^{2}+v_{2}-\frac{t}{2} .
$$

Considering the equilibrium value of advertising and market share by each platform, and using $z \equiv\left(v_{1}-v_{2}\right) / t$, and $k \equiv \gamma / \delta$, we obtain the social welfare for when both platforms are private, which is as follows:

$$
W^{*}=t \frac{9(4 k-3)+18 z+(4 k+1) z^{2}}{36 t}+v_{2}-\frac{t}{2}
$$

Because $k \equiv \gamma / \delta$, social welfare increases with the revenue per ad per viewer $\gamma$ and decreases with nuisance cost, $\delta$ because platforms' profits depend positively on $\gamma$ and negatively on $\delta$, whereas consumer surplus is independent of $\gamma$ but depends negatively on $\delta$.

To facilitate understanding of subsequent welfare comparisons, let us analyse the welfare distortions present in the private duopoly. In particular, (6) makes it easy to observe that if $k \equiv \gamma / \delta<1$ (advertising is harmful), a social planner that maximises welfare with respect to $a_{1}$ and $a_{2}$ would choose zero advertising levels, which in turn,

\footnotetext{
8 These results coincide with those obtained by Peitz and Valletti (2008).

${ }^{9}$ Recall that $x_{2}=1-x_{1}$.
} 
yields the first-best level for the market share of firm 1, which is provided by $x_{1}^{o}=$ $\frac{v_{1}-v_{2}+t}{2 t}=\frac{z+1}{2}$. Therefore, there are two types of distortions in the private duopoly: first, what we might call the "advertising distortion effect", arising from the presence of harmful advertising $\left(a_{i}^{*}>a_{i}^{o}=0\right)$, and second, the "audience distortion effect", arising from sub-optimal audience distribution between platforms $\left(x_{1}^{*}-x_{1}^{o}=-\frac{2}{3} z\right)$. In particular, if the quality differential of platform 1 is positive, then its equilibrium market share is lower than it is at the first-best level. It is interesting to note that according to (1), alleviating "audience distortion" implies a reduction in the advertising gap $\left(a_{1}-a_{2}\right),{ }^{10}$ whereas reducing "advertising distortion" involves a reduction in advertising levels. In the following section we will investigate these two distortion effects in the case of a mixed duopoly.

\section{The mixed duopoly model}

In this section, we will assume that platform 1 is a publicly owned firm that maximises social welfare, whereas platform 2 is a private firm that maximises its profits. Substituting (1) in (6) and maximising the resulting welfare function with respect to $a_{1}$, we obtain the reaction function of publicly owned platform 1 , which is as follows:

$$
a_{1}^{B R}\left(a_{2}\right)=\max \left\{a_{2}+\frac{k-1}{\delta(2 k-1)}\left(v_{1}-v_{2}+t\right), 0\right\}
$$

This function can be interpreted in terms of the two distortionary effects described in the previous section. Note that if $k=1$, then only the "audience distortion effect" appears and the optimal advertising choice made by the platform implies the selection of the same level of advertising as its competitor, which in this case, yields a first-best solution. However, if $k \neq 1$, then the "advertising distortion effect" is also present and the first-best solution cannot be achieved in equilibrium, as will be shown in this section. In particular, if $k<1$, advertising is harmful and the publicly owned platform faces a trade-off between two objectives: reducing the "audience distortion effect" implies a reduction in the advertising gap $\left(a_{1}-a_{2}\right)$ but the need to alleviate "advertising distortion" suggests a reduction in advertising to a level below that of the rival.

Note that platform 2's reaction function is the same as that in the previous section because it continues to be a private firm.

In the following analysis, we will maintain the following

Assumption $1 k>1 / 2$ and $z \in(-1,1)$.

The condition $k>1 / 2$ is necessary to ensure the second order condition for welfare maximization by platform 1 , whereas $z \in(-1,1)$ is needed for positive market shares

\footnotetext{
10 To understand this result, recall that $x_{1}^{o}=\frac{v_{1}-v_{2}+t}{2 t}$, which, combined with (1), implies that $x_{1}-x_{1}^{o}=$ $\frac{\delta\left(a_{1}-a_{2}\right)}{2 t}$. This inference is drawn because when the advertising differential is zero, each viewer chooses his/her most preferred program, which is optimal, but with a positive or negative advertising differential, viewers tend to shift towards the platform with a lower level of advertising.
} 
for both platforms in the mixed duopoly. ${ }^{11}$ The following lemma collects the NE levels for the main endogenous variables in this section.

Lemma 1 Under Assumption 1, both firms are active in the mixed duopoly and the $N E$ values for advertising, market shares, and profits are as follows:

Case (a): $z<4 k-3$ :

$$
\begin{aligned}
& a_{1}^{\prime}=\frac{(4 k-3) t-\left(v_{1}-v_{2}\right)}{\delta(2 k-1)} ; a_{2}^{\prime}=\frac{(3 k-2) t-k\left(v_{1}-v_{2}\right)}{\delta(2 k-1)} ; \\
& a^{\prime}=a_{1}^{\prime}+a_{2}^{\prime}=\frac{(7 k-5) t-(k+1)\left(v_{1}-v_{2}\right)}{\delta(2 k-1)} ; \\
& x_{1}^{\prime}=\frac{k\left(v_{1}-v_{2}+t\right)}{2(2 k-1) t} ; x_{2}^{\prime}=\frac{(3 k-2) t-k\left(v_{1}-v_{2}\right)}{2(2 k-1) t} ; \\
& \pi_{1}^{\prime}=\frac{k^{2}\left[(4 k-3) t-\left(v_{1}-v_{2}\right)\right]\left(v_{1}-v_{2}+t\right)}{2(2 k-1)^{2} t} ; \\
& \pi_{2}^{\prime}=\frac{k\left[(3 k-2) t-k\left(v_{1}-v_{2}\right)\right]^{2}}{2(2 k-1)^{2} t} .
\end{aligned}
$$

Case (b): $z \geq 4 k-3:$

$$
\begin{aligned}
& a_{1}^{\prime}=0 ; a_{2}^{\prime}=\frac{\left(v_{2}-v_{1}+t\right)}{2 \delta} ; \\
& a^{\prime}=a_{1}^{\prime}+a_{2}^{\prime}=\frac{\left(v_{2}-v_{1}+t\right)}{2 \delta} ; \\
& x_{1}^{\prime}=\frac{\left(v_{1}-v_{2}+3 t\right)}{4 t} ; x_{2}^{\prime}=\frac{v_{2}-v_{1}+t}{4 t} ; \\
& \pi_{1}^{\prime}=0 ; \\
& \pi_{2}^{\prime}=\frac{\left(v_{2}-v_{1}+t\right)^{2}}{8 \delta t} .
\end{aligned}
$$

Proof See Appendix.

As previously explained, note that both the "audience distortion effect" and the "advertising distortion effect" arise in equilibrium. In particular, if $z<4 k-3$ and $k<1$, then the audience distortion effect is determined by $x_{1}^{\prime}-x_{1}^{o}=\frac{(k-1)(z+1)}{2(2 k-1)}$, which means that the NE audience of platform 1 is too small, compared with the first best. Obviously, because $a_{1}^{\prime}>0$, and $a_{2}^{\prime}>0$, advertising levels at the NE are too large, from the social welfare perspective.

As in the private duopoly, platform 2 establishes more ads and obtains a larger audience when its quality increases. However, publicly owned platform 1 operates in contrast to a private platform, as observed in the following proposition.

11 Under the mixed duopoly regime, it can be shown that if $z \geq 1$, only the private platform is active, whereas if $z \leq-1$, only the publicly owned platform is active. Also, note that Assumption 1 ensures positive market shares for both firms in the private duopoly (see expressions in (4)). 
Proposition 3 In the case of competition between a publicly owned platform and a private platform, the advertising levels of both platforms decrease with the quality differential $\left(v_{1}-v_{2}\right)$ of the publicly owned platform.

Proof See Appendix.

Note that if advertising is harmful $(k<1)$, the reaction functions of both firms shift downwards as the quality differential increases, which obviously implies a reduction in both advertising levels. Intuitively, if the quality differential is large, platform 1's audience is very large and it has great interest in reducing its level of harmful advertising. Interestingly, the previous proposition holds even if advertising is socially desirable $(k>1)$. The intuition behind this result can be explained by considering two effects associated with an increase in the quality differential $\left(v_{1}-v_{2}\right)$ when $k>1$ : On the one hand, as shown in expression (8), the public firm tends to increase its advertising level because the social desirability of advertising increases with its audience, but on the other hand, the private platform tends to reduce its advertising because of the increased quality of its rival. However, the second effect (which is negative) prevails over the first one (which is positive) because the public channel's best-reply function (8) is steeper than that corresponding to the private one (3). Intuitively, the publicly owned platform is more sensitive to its rival's advertising because it tends to adjust its advertising level to find an optimal distribution of audiences between both platforms.

Surprisingly, in the current debate on the optimal level of advertising in the broadcasting industry, the quality levels of the programmes offered tend to be ignored. However, as our previous proposition illuminates, this debate is meaningless without consideration of the crucial role of the quality differential between the publicly owned and private platforms. In particular, our result suggests that rather than direct intervention in advertising regulation, a decrease in advertising levels in the broadcasting industry can be achieved through improvement in the quality of the programmes offered by the publicly owned platform. ${ }^{12}$

Using (4), (9) and (10), the following result holds with regard to market shares:

Proposition 4 The market share of platform 1 at the NE of both the private and mixed duopoly increases with the quality differential $v_{1}-v_{2}$, but market share's sensitivity to this quality differential is greater in the mixed duopoly than in the private one.

Proof See Appendix.

Intuitively, a larger quality differential tends to render a larger market share of the high-quality platform socially desirable. This effect is better captured by the publicly owned platform because the private platform is interested in increasing its advertising revenues, which tends to decrease its market share.

As explained in the Appendix, using (9) and (10), straightforward calculations provides the following result, illustrated in the $(k, z)$ space in Fig. 1.

Proposition 5 At the NE of the mixed duopoly in which both platforms are active, the following properties hold:

\footnotetext{
12 See González-Maestre and Martínez-Sánchez (2012) for the analysis of a broadcasting duopoly and the endogenous choice of platform quality.
} 


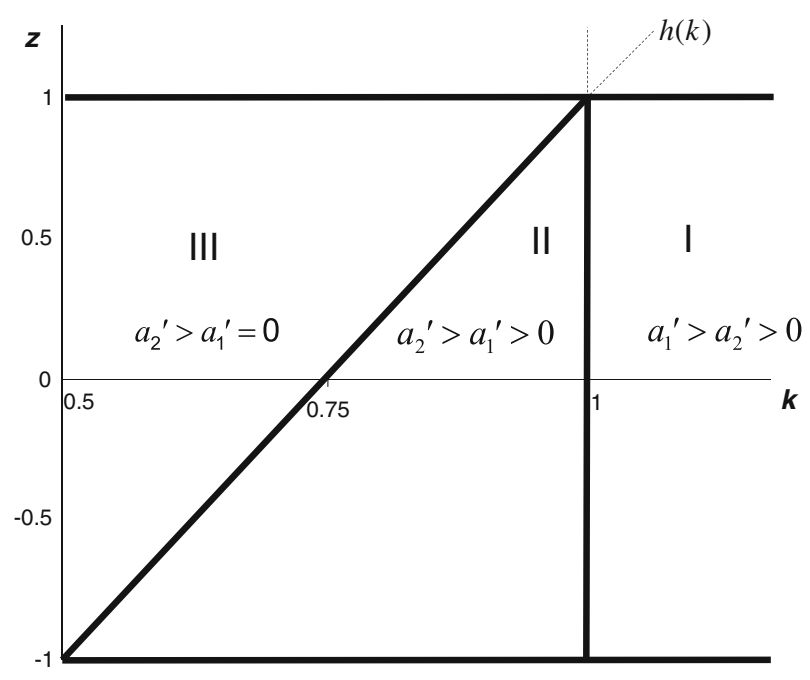

Fig. 1 Advertising comparisons in the mixed duopoly

i) If advertising is socially desirable $(k>1)$, then the publicly owned platform undertakes more advertising than the private platform.(See region (I)).

ii) If advertising is socially harmful $(k<1)$, then the publicly owned platform undertakes less advertising than the private platform. (See regions (II) and (III)).

iii) Moreover, if advertising is socially harmful and the quality differential of the public platform is sufficiently large relative to social preferences for advertising $(z \geq h(k)=4 k-3)$, then the NE of the mixed duopoly implies an "advertisingfree” publicly owned platform. (See region (III))

Proof See Appendix.

The previous result is explained by the two effects that advertising exerts on welfare: On the one hand, advertising has a direct effect, captured by $k$, which depends on the private profits associated with advertising (measured by $\gamma$ ) and the nuisance costs (measured by $\delta$ ), but on the other hand, advertising also has an indirect effect on welfare by affecting the distribution of audience shares between the two platforms. Obviously, because of the direct effect, the publicly owned platform undertakes a greater level of advertising than the private platform if and only if advertising is socially profitable (region I). However, note that the interplay between the direct and indirect effect explains why advertising by the publicly owned platform is positive in region (II), despite the harmful direct effect in this region. This interplay is positive because the negative direct impact exerted by advertising on welfare is outweighed by the positive effect associated with the fact the publicly owned platform's advertising increases the size of the private platform audience, which is socially profitable if the quality differential of the publicly owned platform is small (compared with $k$ ).

Interestingly, region (III) facilitates the identification of the cases in which an "advertising-free" public platform is actually an optimal decision (in terms of a NE of the game). Intuitively, for this result to hold, advertising must have a direct harmful 
effect $(k<1)$, but in addition, region (III) requires the quality differential of the publicly owned platform to be sufficiently large. Thus, a policy implication of our model is that the case for an "advertising-free" publicly owned platform implies that the publicly owned platform has sufficiently high quality compared with its rival. Otherwise, the recent policies mentioned in the introduction that are used by some EU countries would not necessarily be welfare-enhancing even if advertising has a direct harmful effect.

\section{Private versus mixed duopoly}

We are mainly interested in determining which setting, a private or mixed duopoly, is better from a social perspective. However, to aid the understanding of the basic intuition behind the welfare comparisons between the regimes, it is useful to consider the comparison between the NE advertising levels in each of the previous models. Easy computations indicate the following:

Proposition 6 The individual and total advertising levels in the mixed duopoly are greater (respectively lower) than they are in the private duopoly if and only if $z$ is below (and, respectively, above) the function $f(k) \equiv \frac{3(k-1)}{k+1}$. Formally,

$$
a_{i}^{\prime} \gtreqless a_{i}^{*} \leftrightarrow z \lesseqgtr f(k) \equiv \frac{3(k-1)}{k+1} ; i=1,2
$$

Proof See Appendix.

Proposition 6 is reflected in Fig. 2, in which there are two relevant regions: In the region above the function $z=f(k)$, advertising levels under the mixed duopoly are smaller than they are under the private duopoly, and the opposite property holds in the region below $f(k)$. The intuition behind Proposition 6 is as follows: a publicly owned platform's incentive to undertake advertising decreases with both the nuisance cost (which is inversely related to $k \equiv \gamma / \delta$ ) and the quality differential $z$. As a

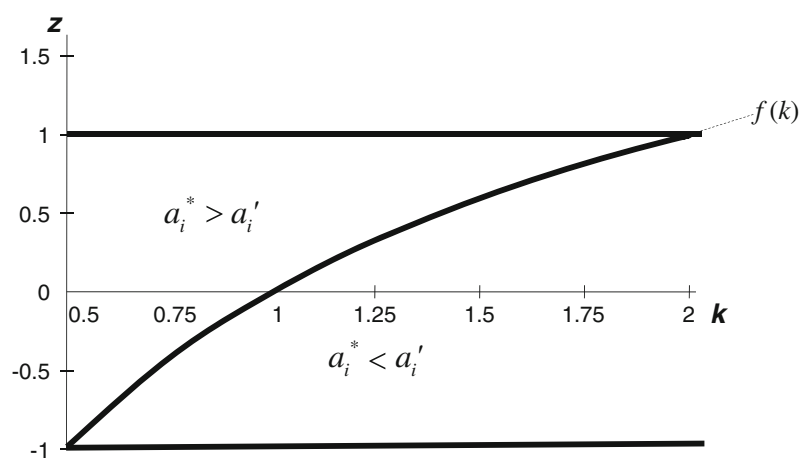

Fig. 2 Advertising comparisons between mixed and private duopoly 
result, the larger $k$ and the smaller $z$ are, the more likely it is that the market is in the region where the mixed duopoly involves more advertising (note that the function $z=f(k)$ is strictly increasing). In our subsequent analysis, we will observe that the welfare comparisons between the two models are very closely related to the previous advertising comparisons.

As in Sect. 2, we calculate social welfare in the mixed duopoly, which is represented by the expression (6). Thus, considering the equilibrium value of advertising and market share in (9) and (10) and using $z \equiv\left(v_{1}-v_{2}\right) / t$, we determine the social welfare in each case:

Case (a): $z<4 k-3$ :

$$
W^{\prime}=t \frac{4(k-1)[(3 k-2)-k z]+k^{2}(z+1)^{2}}{4(2 k-1)}+v_{2}-\frac{t}{2} .
$$

Case (b): $z \geq 4 k-3$ :

$$
W^{\prime}=t \frac{8(k-1)(1-z))+[(1+2 k) z+(1-k)](z+3)}{16}+v_{2}-\frac{t}{2} .
$$

We now calculate the difference in social welfare between the private and the mixed duopoly for each of the cases collected in Lemma 1:

Case (a): $z<4 k-3$ :

$$
\frac{W^{\prime}-W^{*}}{t}=\frac{45(k-1)^{2}-18\left(k^{2}-1\right) z+(k+1)^{2} z^{2}}{36(2 k-1)} .
$$

Case (b): $z \geq 4 k-3$ :

$$
\frac{W^{\prime}-W^{*}}{t}=\frac{1}{144}(z+3)(5 z-42 k+2 k z+39)
$$

As explained in the Appendix, we find that the socially optimal setting depends on the interplay between parameters $z$ and $k$, as illustrated in the following proposition and in Fig. 3.

Proposition 7 For the private duopoly to be socially preferred to a mixed duopoly we require either $(i)$ the combination of socially harmful advertising $(k<1)$ and a negative quality differential (region D) or (ii) the combination of socially beneficial advertising $(k>1)$ and a positive quality differential (region B). In addition, any of the following conditions ensures that the mixed duopoly will be socially preferred to a private duopoly: (iii) socially harmful advertising, combined with a positive quality differential (region A) or (iv) socially beneficial advertising, combined with a low quality differential (region $C$ ).

Proof See Appendix.

Note that under the assumption (the most common in the previous literature) that platforms provide the same quality but different content (only horizontal differentiation 


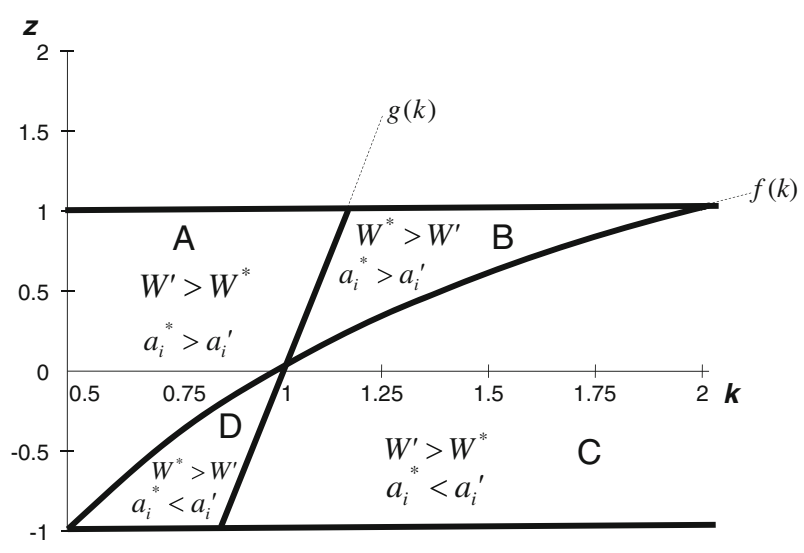

Fig. 3 Social welfare comparisons between mixed and private duopoly

exists), the difference in social welfare between the private and the mixed duopoly (see Eqs. (13), (14)) is reduced to the following expression:

$$
\frac{W^{\prime}-W^{*}}{t}= \begin{cases}\frac{3(39-42 k)}{144} & \text { if } k \leq \frac{3}{4} \\ \frac{5(k-1)^{2}}{4(2 k-1)} & \text { if } k>\frac{3}{4}\end{cases}
$$

which is positive because we assume that $k>1 / 2$. Therefore, when platforms are only horizontally differentiated, a publicly owned platform must exist. However, according to our results, this case is a very particular one, and the optimal government intervention in the broadcasting industry has a crucial dependence on on the interactions between the quality differential of platforms and the relationship between the social value of advertising and nuisance cost. ${ }^{13}$

To understand the intuition behind Proposition 7, let us combine this result with the following facts, which are easily obtained: First, in the private duopoly $a_{1}^{*} \gtreqless a_{2}^{*} \leftrightarrow$ $v_{1} \gtreqless v_{2}$ and second, in the mixed duopoly $a_{1}^{\prime} \gtreqless a_{2}^{\prime} \leftrightarrow k \gtreqless 1$. Considering these facts and the previous proposition, the following result holds:

Corollary 1 The regions represented in Fig. 3 are characterised as follows: In regions $A$ and $C$, the socially optimal market is a mixed duopoly, whereas in regions $B$ and $D$, the socially optimal market is a private duopoly. Moreover, in regions $A$ and $B$, the mixed duopoly undertakes less advertising than the private duopoly, whereas in regions $C$ and $D$, it undertakes more.

The intuition behind the previous corollary is as follows:

\footnotetext{
13 Note that in the other particular case $k=1$, Fig. 3 shows that a mixed duopoly is socially better than a private duopoly. Formally, this particular case resembles the result obtained by Ishibashi and Kaneko (2008) in the reinterpretation of the price levels in their model as the advertising levels in our model. However, our formulation is more general because $k$ can be different from one, which implies that privatisation is not always better than a mixed duopoly, and we consider a straightforward model of two-sided markets.
} 
i) In regions $\mathrm{B}$ and $\mathrm{D}$, the optimal governmental strategy is to choose a private duopoly, but the underlying explanation is different. In region B, a publicly owned platform undertakes a lower level of advertising than a private firm. Intuitively, in this region, advertising is socially profitable ( $k$ is large) and the government chooses the market structure with a higher level of advertising. However, in region $\mathrm{D}$, advertising is socially harmful ( $k$ is small) and a mixed duopoly undertakes more advertising than a private one. Thus, privatisation is the optimal policy.

ii) In regions $\mathrm{A}$ and $\mathrm{C}$, the optimal governmental strategy is a mixed duopoly, but again, for different reasons. Essentially, in region A, the government chooses a mixed duopoly because it yields less advertising than the private duopoly and advertising is relatively harmful. However, in region $\mathrm{C}$, the government chooses a mixed duopoly because it yields more advertising than the private duopoly and advertising is relatively beneficial.

Note that according to Corollary 1 and Fig. 3, the frontier between regions $\mathrm{A}$ and $\mathrm{D}$ is the same as that separating regions $\mathrm{B}$ and $\mathrm{C}$, which in turn, is the same as the frontier that separates the regions determining the sign of the advertising comparisons in Fig. 2. Therefore, the intuition behind welfare comparisons is closely related to the intuition behind advertising comparisons, as previously explained.

It is interesting to examine cases $\mathrm{D}$ and $\mathrm{B}$ in terms of the taxonomy developed by Fundenberg and Tirole (1984). In case D, the optimal governmental choice can be interpreted as an example of the so-called "Lean and Hungry Look": By choosing a private duopoly, the government makes a credible commitment to "underinvest" in advertising (which hurts its rival). However, in case B, the same privatisation strategy is an example of the so-called "Fat Cat" effect: The government chooses a private duopoly as a commitment to "overinvest" in advertising (which is beneficial to its rival).

Therefore, one interesting insight in our analysis is that intervention with a publicly owned channel need not be optimal even when private broadcasters have no comparative advantage in running the business (region B in Fig. 3). This result hinges upon the assumption that the publicly owned broadcaster cannot credibly commit to an advertising level. If the broadcaster could, then it would always be able to replicate the private duopoly outcome by simply choosing what a profit-oriented firm would. That is, if we assume that the publicly owned platform acts as Stackelberg's leader in terms of the advertising choice, then privatisation will never be optimal. However, the credibility of the publicly owned firm's commitment to a given level of advertising cannot be taken for granted. In principle, this commitment could be implemented through the use of a long-run contract between the public channel and the advertisers, but there is not a clear reason for why this instrument cannot also be available for the private platform. In consequence, it appears that our assumption of simultaneous advertising choices is reasonable.

\section{Conclusions and final comments}

In this study, we develop a model in which a publicly owned platform competes with a private one in a free-to-air broadcasting industry in which programmes are 
differentiated in two dimensions: content (horizontal differentiation) and quality (vertical differentiation). In this context, we consider the publicly owned firm's optimal level of advertising and identify the conditions under which the recently adopted policy of an "advertising-free" publicly owned platform is actually an optimal choice from the social welfare perspective.

We also analyse the social profitability of the presence of a publicly owned platform and show that the optimal government intervention in the broadcasting industry has a crucial dependence on the interactions between the quality differential of platforms and the relationship between the social value of advertising and nuisance cost. In particular, we find that the existence of a publicly owned platform can be a social optimum even if it provides lower quality than the private platform. However, we also identify conditions under which a private duopoly is socially better than a mixed duopoly even if the publicly owned platform provides higher quality than its private competitor.

Our results are limited by our assumptions. In particular, we ignore the possibility that platforms will make an endogenous choice of quality, which in turn, would imply the presence of endogenous fixed costs. In fact, this issue is developed in a related paper by González-Maestre and Martínez-Sánchez (2012), where qualities are endogenous. The obvious question is the following: which scenario is more relevant, from the economic policy perspective? In our view, the answer to this question depends on several considerations with regard to the institutional framework determining the timing of decisions. In particular, it appears that both the investment associated with platforms' quality choices and the decision regarding the privatisation of the publicly owned platform are long-run choices, but it is not clear which of the two types of choices is more flexible. Therefore, we believe that the analysis of the two scenarios is meaningful.

Some of the results obtained in our model yield similar insights. In particular, it is shown in González-Maestre and Martínez-Sánchez (2012) that the greater the degree of horizontal product differentiation, the more likely is that a mixed duopoly is socially optimal. A similar result is implicit in our Fig. 3. According to this figure, for any given level of quality differential, a greater degree of horizontal product differentiation makes it more likely that a mixed duopoly is optimal. However, there are some remarkable differences in terms of results and policy implications between the two approaches:

1) Under endogenous qualities, González-Maestre and Martínez-Sánchez (2012) show that a mixed duopoly is socially better than privatisation only if the direct effect of advertising is either very harmful or highly beneficial, whereas privatisation is the optimal policy if advertising is neutral or has a moderate effects on welfare. In contrast, under exogenous qualities we have shown that the mixed duopoly is socially better than privatisation if advertising is neutral.

2) In our model with exogenous qualities, the case for an "advertising-free" publicly owned platform is associated to socially harmful advertising, whereas in the model of endogenous qualities, González-Maestre and Martínez-Sánchez (2012) obtain cases where an "advertising-free" publicly owned platform is optimal even if advertising is socially beneficial. Therefore, the policy implications with respect to the 
advertising regulation in the public platform are substantially different between both scenarios.

There are obviously many relevant issues, related to the advertising market that have not been considered in our model. As explained in Sect. 2, our model relies on the assumption known as competitive bottleneck (Armstrong 2006), which involves constant revenue per ad per viewer (parameter $\gamma$, in our model). This assumption is a standard one in the literature on two-sided markets. A more complex modeling of the advertising market would consider $\gamma$ as an endogenous variable that depends on platforms' competition to attract advertisers. This alternative assumption would complicate the analysis. However, under reasonable conditions, our qualitative conclusions would still hold. For instance, it could be assumed that $\gamma$ is determined by means of an efficient bargaining process between the advertiser and its associated platform in which the bargaining power of each platform is inversely related to the amount of advertising offered by the rival platform, and that in turn, this bargaining power determines the share of profits obtained by each part. Note that allowing $\gamma$ to be endogenous in this way will affect only the distribution of profits between the platform and advertisers, not the platforms' decisions regarding advertising level or the welfare analysis. ${ }^{14}$ In our simplified model, we have also assumed zero costs. Note that with a positive fixed cost, public television will be unable to survive without advertisements unless it receives a transfer from the government. Our implicit assumption is that this transfer is obtained through non-distortionary taxation, but if this were not the case, then the welfare analysis would have to consider the distortion.

The model could also be extended to investigate the combined role of a publicly owned firm and other policy tools. In particular, some European countries establish caps on the number of advertisements. In principle, the availability of this tool could change our results regarding the role of public television. However, as explained in the introduction, the combined effects of lobbying, technological change, and globalisation make it increasingly difficult to implement this tool optimally, which tends to reinforce the role of public television, as noted by Kind et al. (2007).

Lastly, our analysis focuses on a particular economic aspect of broadcasting markets and abstracts from other economic and institutional issues. In particular, we have assumed that the only aim of the public intervention in broadcasting markets is to maximise total welfare and that this welfare depends on viewers' valuation of programme quality. ${ }^{15}$ However, it is rather obvious that in practice, there are other plausible objectives justifying the presence of a publicly owned platform, including the provision of "universal contents", cultural and educational diffusion, political reasons, and many

\footnotetext{
14 As noted by a referee, the competition between public and private televisions to attract announcers is a relevant issue in the market place, which might explain the interest of private television in the recent decisions of some European public television platforms to eliminate advertising. However, the recent empirical work by Filistrucchi et al. (2012) on the effects of the advertising ban on French public television appears to indicate that the common expectation that the ban would favour private TV channels has not been confirmed in practice.

15 Another interesting extension of the model could consider a generalised welfare objective for which consumer surplus and platforms' profits have different valuation in the objective function of the publicly owned firm. In particular, if the public TV overvaluates viewer utility, then it will tend to reduce advertising, which makes it more likely an equilibrium with "advertising-free" public TV.
} 
others. In particular, our results could change substantially if the regulator's valuation of programme quality differs from the viewers', which could be justified by political or cultural objectives.

Open Access This article is distributed under the terms of the Creative Commons Attribution License which permits any use, distribution, and reproduction in any medium, provided the original author(s) and the source are credited.

\section{Appendix}

Proof of Proposition 1 According to (4), $\frac{\partial a_{i}^{*}}{\partial\left(v_{i}-v_{j}\right)}=\frac{1}{3 \delta}>0, \frac{\partial x_{i}^{*}}{\partial\left(v_{i}-v_{j}\right)}=\frac{1}{6 t}>0$ and $\frac{\partial \pi_{i}^{*}}{\partial\left(v_{i}-v_{j}\right)}=\frac{k\left(v_{i}-v_{j}+3 t\right)}{9 t}>0$, which is ensured by $x_{i}^{*} \geq 0$.

Proof of Proposition 2 From (4), it follows that $\frac{\partial \pi_{i}^{*}}{\partial t}=\frac{k\left(v_{i}-v_{j}+3 t\right)\left(v_{j}-v_{i}+3 t\right)}{18 t^{2}}>0$, which is ensured by $x_{i}^{*} \geq 0$. In addition, $\frac{\partial \pi_{i}^{*}}{\partial k}=\frac{\left(v_{i}-v_{j}+3 t\right)^{2}}{18 t^{2}}>0($ recall that $k=\gamma / \delta)$.

Proof of Lemma 1 Using (3) and (8), we can calculate the NE levels of advertising in expressions (9) and (10), which, substituted in (1) and (2), yield the NE market shares and profits collected in (9) and (10), respectively.

To observe that market shares are positive for both firms, note that combining Assumption 1 with (9) and (10) ensures that $x_{1}^{\prime}>0$. Now, let us consider the value of $x_{2}^{\prime}$. If $k \geq 1$ then according to Assumption 1, case (a) holds, and using (9), we have $x_{2}^{\prime}>0 \longleftrightarrow z<3-\frac{2}{k}$, which is ensured by Assumption 1. If $k<1$ and case (a) hold, then $x_{2}^{\prime}>0 \longleftrightarrow z<3-\frac{2}{k}$, which is ensured by the condition $z<4 k-3$, which defines case (a). To obtain this result, note that if $k<1$ then $3-\frac{2}{k}<4 k-3$, which completes the proof.

Proof of Proposition 3 According to (9), we have that in case (a), $\frac{\partial a_{1}^{\prime}}{\partial\left(v_{1}-v_{2}\right)}=$ $-\frac{1}{\delta(2 k-1)}<0$ and $\frac{\partial a_{2}^{\prime}}{\partial\left(v_{1}-v_{2}\right)}=-\frac{k}{\delta(2 k-1)}<0$, which is ensured by Assumption 1. In case (b) we have $\frac{\partial a_{2}^{\prime}}{\partial\left(v_{1}-v_{2}\right)}=-\frac{1}{2 \delta}<0$.

Proof of Proposition 4 Case (a): Using (4) and (9), we obtain $\frac{\partial x_{1}^{*}}{\partial\left(v_{1}-v_{2}\right)}=\frac{1}{6 t}<$ $\frac{\partial x_{1}^{\prime}}{\partial\left(v_{1}-v_{2}\right)}=\frac{k}{2(2 k-1) t}$, which is ensured by $k>1 / 2$. Case (b): Using (4) and (10), we determine that $\frac{\partial x_{1}^{*}}{\partial\left(v_{1}-v_{2}\right)}=\frac{1}{6 t}<\frac{\partial x_{1}^{\prime}}{\partial\left(v_{1}-v_{2}\right)}=\frac{1}{4 t}$.

Proof of Proposition 5 Recall that according to Lemma 1, both platforms are active under Assumption 1, which includes regions (I), (II) and (III) in Fig. 1. Note that according to cases (a) and (b), shown in expressions (9) and (10), the frontier between regions (II) and (III) is determined by the equation $z=4 k-3$. At the RHS of this equation, which includes regions (I) and (II), expressions at (9) are the relevant ones for the advertising levels. By using these expressions, we determine that $a_{1}^{\prime} \gtreqless$ $a_{2}^{\prime} \longleftrightarrow k \gtreqless 1$, which proves parts (i) and (ii). Part (iii) originates from the fact that $a_{1}^{\prime}>0 \longleftrightarrow z<4 k-3$, which implies that in region (III), we have $a_{1}^{\prime}=0$. 
Proof of Proposition 6 By using (4), (9), and (10), it follows that $a_{i}^{\prime}>a_{i}^{*} \longleftrightarrow a^{\prime}>$ $a^{*} \longleftrightarrow z<\frac{3(k-1)}{k+1}$.

Proof of Proposition 7 Case (a): Given that $k>1 / 2$ and $t>0$, the sign of the difference in social welfare is the same as the sign of the numerator of expression (13). By using the condition $\frac{W^{\prime}-W^{*}}{t}=0$, we obtain the following pair of solutions:

$$
z=f(k)=\frac{3(k-1)}{k+1} ; z=g(k)=\frac{15(k-1)}{k+1}
$$

From these two functions, shown in Fig. 3, it is easy to obtain the sign of $\frac{W^{\prime}-W^{*}}{t}$ in each of the four regions illustrated in Fig. 3 (B, C, D, and the part of region A that is consistent with this case).

Case (b): By using (14), it follows that the sign of $\frac{W^{\prime}-W^{*}}{t}$ is provided by $5 z-42 k+$ $2 k z+39$, which is strictly positive in this case. To obtain this result, note first that $5 z-42 k+2 k z+39>0 \leftrightarrow z>l(k) \equiv \frac{1}{2 k+5}(42 k-39)$, and second, that in our case $z>h(k) \equiv 4 k-3>l(k) \equiv \frac{1}{2 k+5}(42 k-39)$, the last inequality being satisfied for the range of values established in Assumption 1. Therefore, $\frac{W^{\prime}-W^{*}}{t}>0$ in the part of region $\mathrm{A}$ that is consistent with this case.

\section{References}

Alcock J, Docwra G (2005) A simulation analysis of the market effect of the Australian Broadcasting Corporation. Inf Econ Policy 17(4):407-427

Anderson SP (2007) Regulation of television advertising. In: Seabright P, Von Hagen J (eds) The economic regulation of broadcasting markets. Cambridge University Press, London

Anderson SP, Coate S (2005) Market provision of broadcasting: a welfare analysis. Rev Econ Stud 72:947972

Anderson SP, Gabszewicz JJ (2006) The media and advertising: a tale of two-sided markets. In: Ginsburgh Victor A, Throsby D (eds) Handbook of the economics of art and culture, vol 1. Elsevier B.V, Amsterdam

Armstrong M (2005) Public service broadcasting. Fisc Stud 26(3):281-299

Armstrong M (2006) Competition on two-sided markets. RAND J Econ 37(3):668-691

Bel G, Domènech L (2009) What influences advertising price in television channels?: An empirical analysis on the Spanish market. J Media Econ 22(3):164-183

Coase R (1966) The economics of broadcasting and government policy. Am Econ Rev 56:440-447

Crampes C, Haritchabalet C, Jullien B (2009) Advertising, competition and entry in media industries. J Ind Econ 57(1):7-31

Filistrucchi L, Luini L, Mangani A (2012) Banning ads from prime-time state television: lessons from France, mimeo

Fundenberg D, Tirole J (1984) The fat-cat effect, the puppy-dog ploy, and the lean and hungry look. Am Econ Rev 74:361-366

Gabszewicz JJ, Laussel D, Sonnac N (2004) Programming and advertising competition in the broadcasting industry. J Econ Manag Strategy 13(4):657-669

Gantman N, Shy O (2007) Broadcasting competition and advertising quality: a two-sided market approach, mimeo

González-Maestre M, Martínez-Sánchez F (2012) Quality choice and advertising regulation in broadcasting markets, WP-AD 2012-03, IVIE

Ishibashi K, Kaneko T (2008) Partial privatization in mixed duopoly with price and quality competition. J Econ 95(3):213-231

Kind HJ, Nilssen T, Sørgard L (2007) Competition for viewers and advertisers in a TV oligopoly. J Media Econ 20(3):211-233 
Kumar A, Saha B (2008) Spatial competition in a mixed duopoly with one partially nationalized firm. J Comp Econ 36(2):326-341

Lin P (2011) Market provision of program quality in the television broadcasting industry. BE J Econ Anal Policy 11(1 Contributions). Article 17

Martínez-Sánchez F (2011) Bertrand competition in a mixed duopoly market: a note. Manch Sch 79(6): 1058-1060

Peitz M, Valletti TM (2008) Content and advertising in the media: pay-tv versus free-to-air. Int J Ind Organ 26:949-965

Sanjo Y (2009) Bertrand competition in a mixed duopoly market. Manch Sch 77(3):373-397

Sanz E (2012) Statistical, ecosystems and competitiveness analysis of the media and content industries: European television in the new media landscape. In: Bogdanowicz M, Simon JP (eds) European Commission, Joint Research Centre, Institute for Prospective Technological Studies. Available at ftp://ftp. jrc.es/pub/EURdoc/JRC76569.pdf

Stühmeier T, Wenzel T (2012) Regulating advertising in the presence of public service broadcasting. Rev Netw Econ 11(2). Article 1

Wilbur KC (2008) A two-sided empirical model of television advertising and viewing markets. Mark Sci 27(3):356-378 